\title{
Evolution of Asian and African Lygosomine Skinks of the Mabuya Group (Reptilia: Scincidae): A Molecular Perspective
}

\author{
Masanao Honda ${ }^{1 *}$, Hidetoshi Ota ${ }^{2}$, Mari Kobayashi ${ }^{1}$, Jarujin Nabhitabhata ${ }^{3}$, \\ Hoi-Sen Yong ${ }^{4}$ and Tsutomu Hikida ${ }^{1}$ \\ ${ }^{1}$ Department of Zoology, Graduate School of Science, Kyoto University, \\ Sakyo, Kyoto, 606-8502 Japan, \\ ${ }^{2}$ Tropical Biosphere Research Center, University of the Ryukyus, \\ Nishihara, Okinawa, 903-0213 Japan, \\ ${ }^{3}$ National Science Museum, Rasa Tower, Fl 16, 555 Phahonyothin Road, \\ Bangkok, 10900 Thailand and \\ ${ }^{4}$ Department of Zoology, University of Malaya, \\ Kuala Lumpur, 59100 Malaysia
}

\begin{abstract}
Phylogenetic relationships among Asian and African lygosomine skinks of the Mabuya group were inferred from 825 base pairs of DNA sequences of mitochondrial 12S and 16S rRNA genes. Results indicated the presence of two distinct lineages within this group, of which one consisted of Lamprolepis and Lygosoma, and the other of Apterygodon, Dasia, and Asian and African Mabuya. Within the latter, African species of Mabuya first diverged from the remainder, leaving the Asian congeners together with the Apterygodon-Dasia clade. Our results, while suggesting the non-monophyly of the genus Mabuya, do not support the currently prevailing phylogeographical hypothesis which assumes the independent origins of Lamprolepis and Lygosoma from the Asian Mabuya-like stock. On the other hand, our results suggest that morphological and karyological similarities between the Apterygodon-Dasia clade and Lamprolepis are attributable to symplesiomorphy, while their ecological similarity to convergence. Morphological and karyological character states unique to Apterygodon are supposed to have evolved from those exhibited by Dasia.
\end{abstract}

\section{INTRODUCTION}

The subfamily Lygosominae contains over 600 species (Greer, 1970a; Matsui, 1992; Zug, 1993). Within this subfamily, three evolutionary lineages (i.e., Eugongylus, Mabuya and Sphenomorphus groups) are recognized on the morphological, karyological and immunogenetic grounds (e.g., King, 1973, 1990; Greer, 1979, 1989; Hardy, 1979; Baverstock and Donnellan, 1990; Donnellan, 1991a, b; Ota et al., 1988, 1991, 1995, 1996). Of these, the Mabuya group is mainly distributed in temperate and tropical Asia, central and southern Africa, and Australia. Mabuya, the largest genus of this group with broadest range, also occurs in Madagascar and South America including the West Indian Islands, but is not distributed in Australia (Boulenger, 1887; Matsui, 1992; Nussbaum and Raxworthy, 1994).

Three arboreal genera (Apterygodon, Dasia [sensu stricto] and Lamprolepis) and one terrestrial or semi-fossorial genus (Lygosoma [sensu Greer, 1977]) have been assigned to the Mabuya group together with Mabuya and a few other African

\footnotetext{
* Corresponding author: Tel. +81-75-753-4091; FAX. +81-75-753-4114.
}

and Australian genera. Of these, the former three taxa had been grouped together as the genus Dasia sensu lato (Smith, 1937; Mittleman, 1952), when Greer (1970b) proposed the current generic arrangements on the basis of morphological characters. He also argued that the Apterygodon-Dasia lineage and the Lamprolepis lineage had evolved independently from a Mabuya-like stock in Southeast Asia. With an extension of this view, Greer (1977) considered that, besides the genus Mabuya, those two arboreal lineages, Lygosoma, Australian members of the Mabuya group, the Eugongylus group, and the Sphenomorphus group constitute six phylogenetic lineages independently derived from the Asian Mabuya-like stock (he argued for the subsequent derivations of the African endemic genera of the Mabuya group from the Mabuya-like stock within this continent). However, the chronological order of these divergences was not hypothesized in that work. Later, Australian members of the Mabuya group, the Eugongylus group and the Sphenomorphus group were attributed to divergences earlier than that in Asian and African members of the Mabuya group (Greer, 1979, 1989). The remaining three lineages, Apterygodon-Dasia, Lamprolepis and Lygosoma, as well as Mabuya, are still considered as derived from the Mabuya-like stock in Asia (Greer, 1977), although their 
detailed relationships remain uncertain.

The genus Mabuya seems to have first emerged in South or Southeast Asia and then dispersed through Africa onto Madagascar and South America, because a few species from South and Southeast Asia exhibit most primitive states of characters among the extant Mabuya species (Greer, 1977). Although some authors (e.g., Greer, 1977) pointed out the possible non-monophyly of this genus due to its wide distribution and great morphological diversity, no comprehensive phylogenetic analyses have ever been made for the genus and its relatives to verify this prediction.

There have been a number of debates regarding the phylogenetic relationships and classification of lygosomine skinks, and most of relevant arguments have depended on morphological evidence (e.g., Mittleman, 1952; Greer, 1970a, 1974, 1979; Horton, 1972, 1973). However, due to the scarcity of informative characters, it is not easy to formulate a sufficiently reliable phylogenetic hypothesis for this group solely on the morphological ground. Phylogenetic analyses on the basis of molecular data are, therefore, expected to much contribute to the solution of this problem.

We sequenced a part of mitochondrial DNA for representatives of Asian and African Mabuya, and the three other lineages supposedly derived from the Mabuya-like stock in Asia (see above), and analyzed resultant data phylogenetically. The purpose of this study is to reveal the pattern and process in the early evolution of the widespread and apparently substantially diverged Mabuya group in Asia and Africa.

\section{MATERIALS AND METHODS}

Tissues were obtained from eight Southeast Asian species belonging to five genera of the Mabuya group (Apterygodon vittatus, Dasia gricea, D. olivacea, Lamprolepis smaragdina, Lygosoma bowringii, Mabuya longicaudata, $M$. multifasciata and $M$. rudis), and two African Mabuya (M. quiquetaeniata and M. striata) (Table 1, see Appendix for further detail). We selected Eumeces latiscutatus of the subfamily Scincinae, a possible closest relative of Lygosominae (Greer, 1970a), as an outgroup for which tissues were available to us.

Small amounts of livers, removed from anesthetized or dead specimens and stocked at $-80^{\circ} \mathrm{C}$, were homogenized in extraction buffer [150 mM NaCl, $10 \mathrm{mM}$ Tris- $\mathrm{HCl}$ (pH 8.0), $10 \mathrm{mM}$ EDTA, 1\% sodium dodecyl sulfate]. After digesting samples with Proteinase $\mathrm{K}$ $(100 \mu \mathrm{g} / \mathrm{ml})$ at $50^{\circ} \mathrm{C}$ for three hours, DNA was extracted with phenol (three times) and 25:24:1 of phenol/chloroform/isoamyl-alcohol (once), and was precipitated in ethanol with one-tenth volume of $3.0 \mathrm{M}$ sodium acetate $(\mathrm{pH}$ 5.2). Samples resuspended in TE buffer were further purified by RNase digestion $(20 \mu \mathrm{g} / \mathrm{ml})$ at $37^{\circ} \mathrm{C}$ for one hour, followed by ethanol precipitation. DNA amplification and sequencing are described in detail elsewhere (Honda et al., 1999). A part of mitochondrial $12 S$ and $16 S$ rRNA genes was amplified by the polymerase chain reaction (PCR) using primer L1091 (5'-AAACTGGGATTAGATACCCCACTAT-3') and H1478 (5'-GAGGGTGACGGGCGGTGTGT-3'), and L2606 (5'-CTGACCGTGCAAAGGTAGCGTAATCACT-3') and H3056 (5'-CTCCGGTCTGAACTCAGATCACGTAGG3'), respectively (Kocher et al., 1989; Hedges et al., 1993). The numbering system followed that for the human sequence (Anderson et al., 1981).

Alignments for DNA sequences were determined based on maximum nucleotide similarity. We prepared a pairwise matrix of distance by Kimura's (1980) two-parameter model. The neighbor-joining (NJ) method (Saitou and Nei, 1987) was applied to infer relationships among taxa on the basis of the distance matrix. The degree of supports for internal branches of each tree was assessed by 1,000 bootstrap replications (Felsenstein, 1985). These analyses were performed by use of Clustal W 1.4 (Thompson et al., 1994). Maximum parsimony analysis (MP) was also performed using PAUP 3.1.1 with heuristic option (Swofford, 1993). In this analysis, each nucleotide base was regarded as a character and four kinds of salt as different character states. No frequency bias was assumed for transition and transversion. The confidence was assessed by 1,000 bootstrap resamplings (Felsenstein, 1985). In both analyses, gap sites were excluded.

\section{RESULTS}

Aligned sequences from two mitochondrial genes are presented in Fig. 1. The 12S rRNA fragment consisted of 389 total sites, 157 of which were variable. In the 16S rRNA fragment, there were 436 total aligned sites, 144 of which were variable. Intergeneric nucleotide replacements between five lygosomine genera varied from 70 base pairs (bp) (Apterygodon vittatus vs Dasia gricea) to 152 bp (Lamprolepis smaragdina vs Mabuya longicaudata). Nucleotide replacements between congeneric species of Dasia and Mabuya were observed in 73 and 74 bp ( $D$. grecea vs $D$. olivacea from Borneo and Malay Peninsula, respectively), and from $82 \mathrm{bp}$ (M. multifasciata vs $M$. rudis) to $121 \mathrm{bp}$ (M. longicaudata vs $M$. quiquetaeniata or $M$. striata), respectively. Intraspecific nucleotide replacements of $D$. olivacea involved $18 \mathrm{bp}$ (Malay Peninsula vs Borneo), whereas there were no replacements between two samples of L. smaragdina (Guam vs Saipan).

The NJ dendrogram derived from mitochondrial DNA distance matrix (not given) is shown in Fig. 2A. The ingroup portion of this dendrogram was divided into two major clusters, of which one, consisting of Lamprolepis and Lygosoma, was completely supported in bootstrap iterations (100\%). The other

Table 1. Distribution of the genera of the Mabuya group. Asterisk $\left(^{*}\right)$ indicates taxonomic and/or geographic groups studied in the present analysis. (a) including western Oceanian islands; (b) including Madagascar; (c) including West Indies Islands. See Appendix for detailed localities.

\begin{tabular}{lcccc}
\hline \multicolumn{1}{c}{ Genus } & South Asia & Southeast Asia & Africa & South America \\
\hline Apterygodon & & $+^{*}$ & & \\
Dasia & + & $+^{*}$ & & \\
Lamprolepis & & $+^{*, \mathrm{a}}$ & & \\
Lygosoma & & $+^{*}$ & & \\
Mabuya & + & $+^{*}$ & $+^{*}, \mathrm{~b}$ & $+^{\mathrm{c}}$ \\
\hline
\end{tabular}


Eumeces latiscutatus Apterygodon vittatus Dasia gricea

D. olivacea (Malay Pen.) D. olivacea (Borneo) Lamprolepis smaragdina Lygosoma bowringii Mabuya longicaudata M. multifasciata M. quinquetaeniata M. rudis M. striata

Eumeces latiscutatus Apterygodon vittatus Dasia gricea

D. olivacea (Malay Pen.)

D. olivacea (Borneo)

Lamprolepis smaragdina

Lygosoma bowringii

Mabuya longicaudata

M. multifasciata

$M$. quinquetaeniata

M. rudis

M. striata

Eumeces latiscutatus Apterygodon vittatus

Dasia gricea

D. olivacea (Malay Pen.)

D. Olivacea (Malay P
D. olivacea (Borneo)

Lamprolepis smaragdina

Lygosoma bowringii

Mabuya longicauda

M. multifasciata

$M$. quinquetaeniata

M. rudis

M. striata

Eumeces latiscutatus Apterygodon vittatus Aasia gricea

Dasia gricea

D. olivacea (Malay Pen.)
D. olivacea (Borneo)

Lamprolepis smaragdina

Lygosoma bowringii

Mabuya longicaudata

M. multifasciata

M. quinquetaeniata

M. rudis

M. striata

Eumeces latiscutatus Apterygodon vittatus

Dasia gricea

D. olivacea (Malay Pen.)

D. olivacea (Borneo)

Lamprolepis smaragdina

Lygosoma bowringii

Mabuya longicaudata

M. multifasciata

M. quinquetaeniata

M. rudis

M. striata

Eumeces latiscutatus Apterygodon vittatus Dasia gricea

D. olivacea (Malay Pen.)

D. olivacea (Borneo)

Lamprolepis smaragdin

Lygosoma bowringii

Mabuya longicaudata

M. multifasciata

$M$. quinquetaeniata

M. rudis

M. striata
150

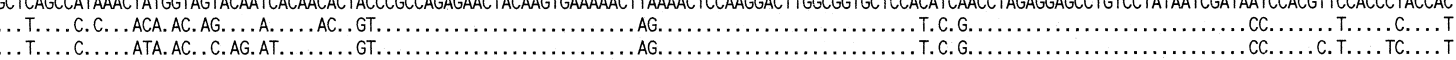
T..........ATA.AC..C. AG. AT.........GT.

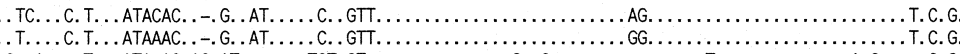

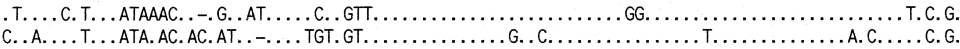

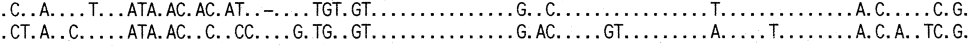

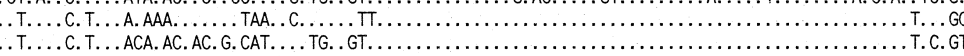

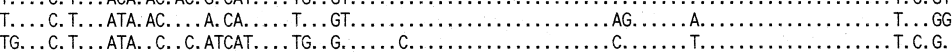

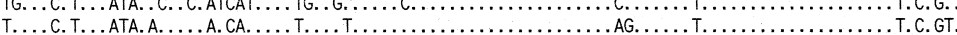

300

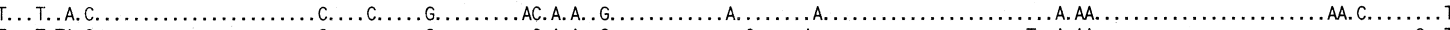

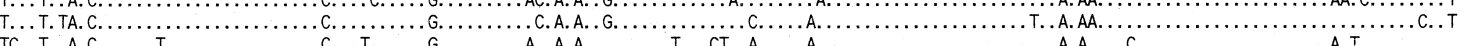

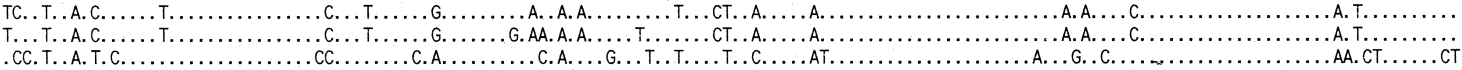

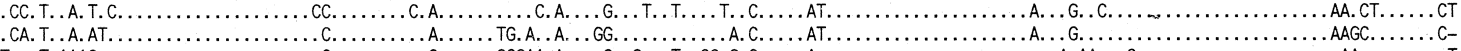

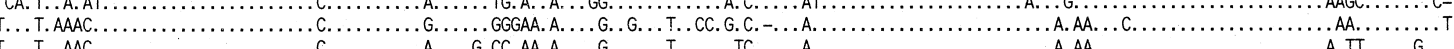

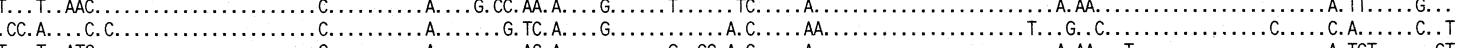

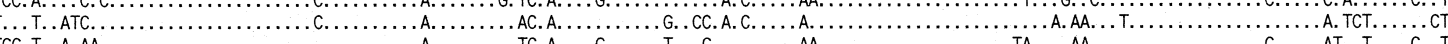

$301-3$

ACGAACAGCCTAATGAAACTTAGGCCAAAAGGCGGATTTAGCAGTAAGACAAGCAAGAAACCCTGTCTTAAACCCGCTCTGGAGCGCGCTGTCTGTAAATAGAGACCAGTATGAACGGCTAAATGAGGACAAACCTGTCTCTTGCAACC

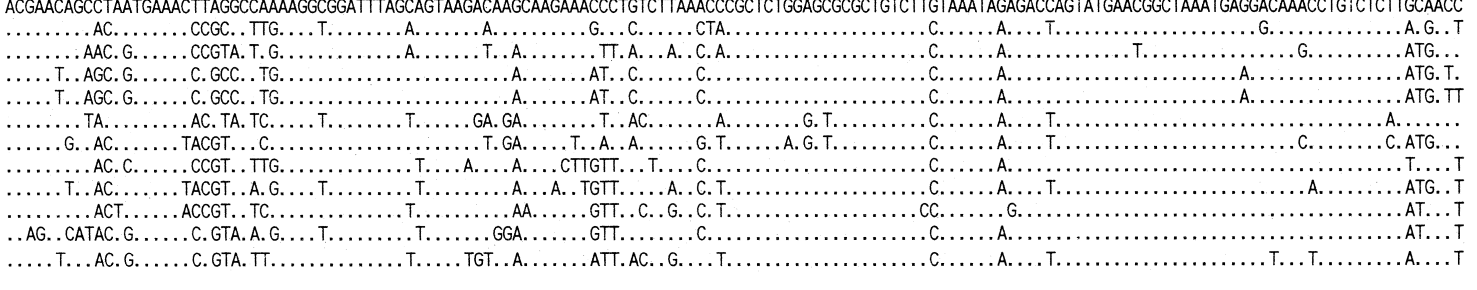

451

AATCAGTGAAACTGATCTCCCGGTCCAAAAGCCGGAATAACCCCATAAGACGAGAAGACCCTGTGGAGCTTAAAACAAGCTACTATGCACCACACAAGCT-GCAACTAGTAAGTAGTITTAAGTTGGGGCGACTTCGGAACCAAAAAAAA

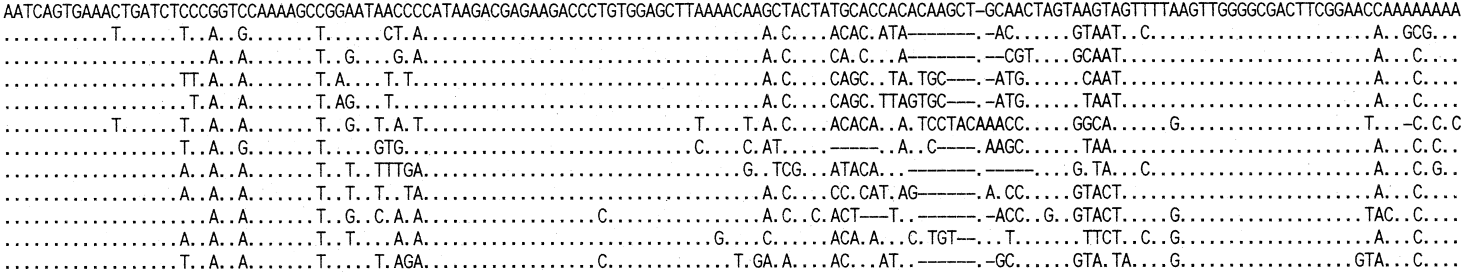

601

CTTCCGAGCACAGAACCACCC-ACTCTTACCAAGACCAACAAGTCAAAG-C-_CCAAAAACGACCCAGT--AACACTGATCAACGAACCAAGTTACCCCAGGGATAACAGCGCCATCTTCTTCAAGAGTTCATATCGACAAGAAGGTTA

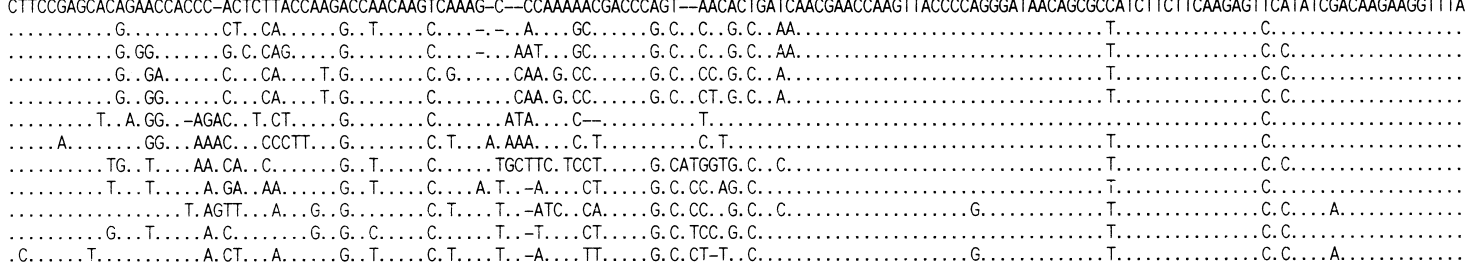

751

CGACCTCGATGTTGGATCAGGACACCCCAATGGTGCAGCCGCTATTAAAGGTTCGTTGTTCAACGATTAACAGT

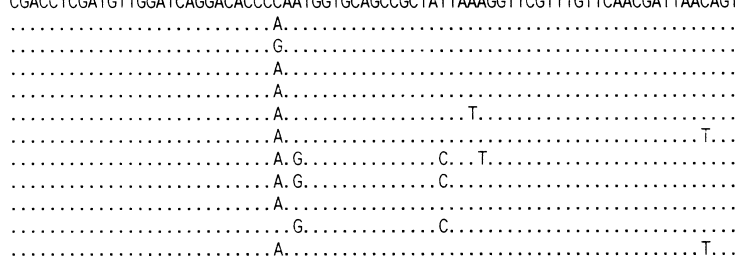

Fig. 1. Aligned sequences of a $825 \mathrm{bp}$ segment of the $12 \mathrm{~S}$ and $16 \mathrm{~S}$ rRNA genes. The initial $389 \mathrm{bp}$ in each row correspond to $12 \mathrm{~S}$ rRNA gene sequence. The 16S rRNA gene sequence begins at the asterisk. Dot indicates an identity with the first sequence; dash denotes a gap.

major cluster, supported in $94 \%$ of bootstrap iterations, contained Apterygodon, Dasia and Mabuya. The latter cluster was further split into two subclusters consisting of African Mabuya (99\%), and Asian Mabuya, Apterygodon and Dasia (71\%), respectively. Within the latter, Apterygodon and Dasia (86\%), and three Asian Mabuya examined (93\%) constituted lower subclusters. Conspecific samples exclusively constituted lowest clusters in all iterations (100\%).

Resultant cladogram of MP (Fig. 2B) showed no substantial inconsistency with the NJ dendrogram in terms of branching topology, although Apterygodon, Dasia and the Asian members of Mabuya did not constituted an exclusive cluster. 
A

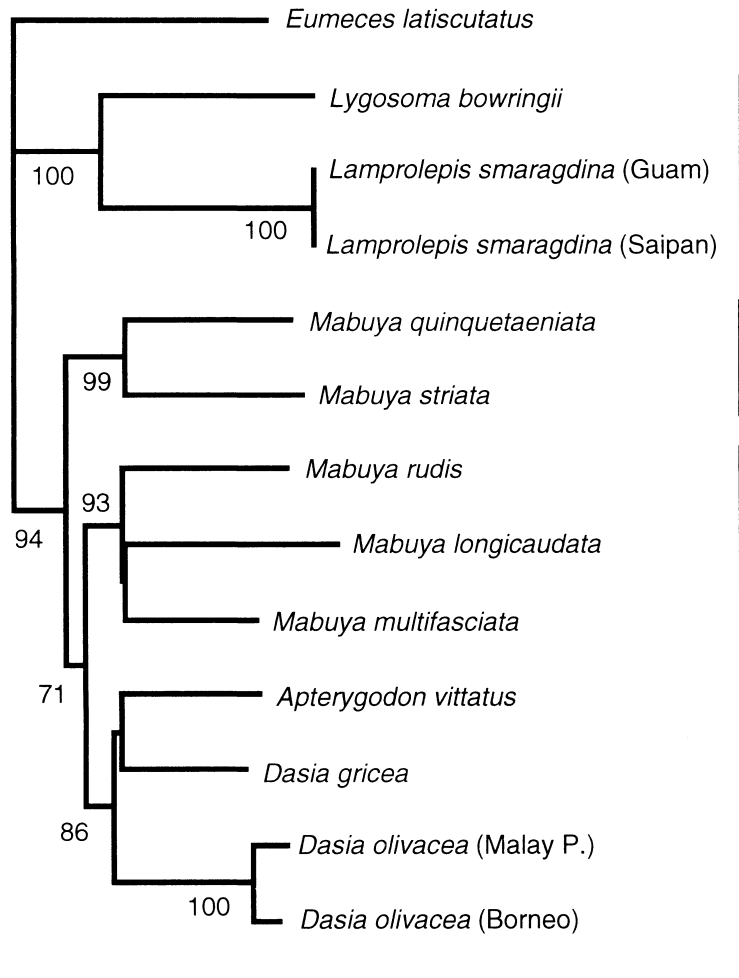

B

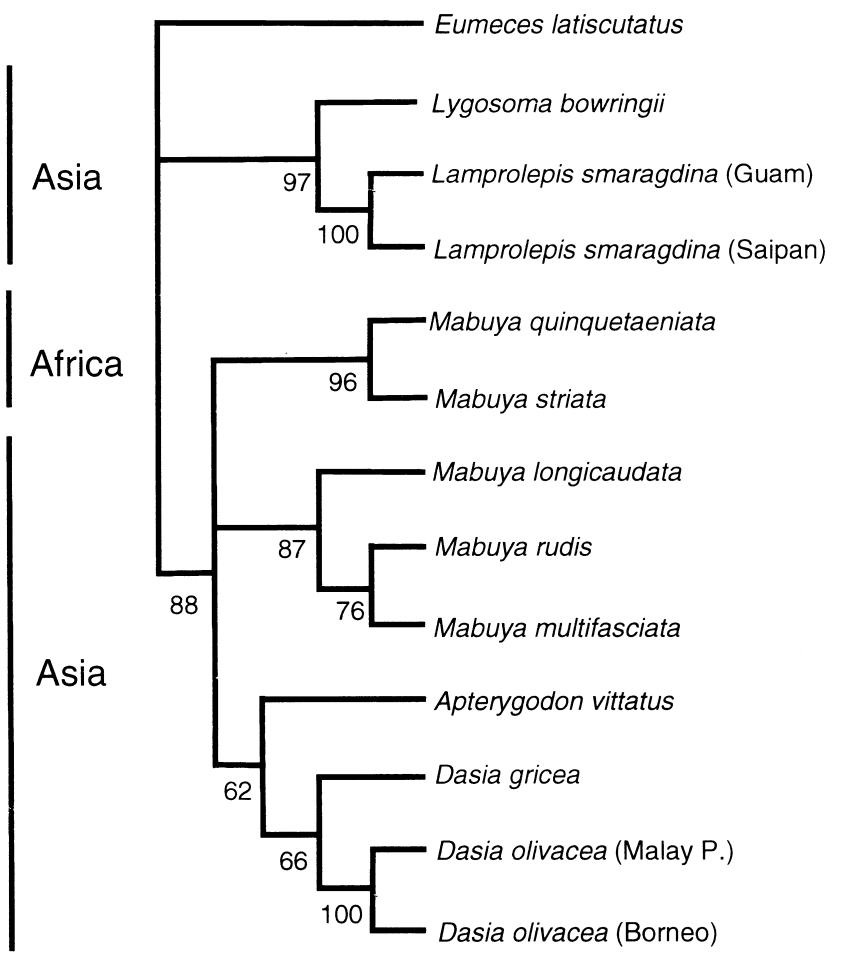

0.1

Fig. 2. (A) Neighbor-joining (NJ) dendrogram derived from distance matrix from $12 \mathrm{~S}$ and $16 \mathrm{~S}$ rRNA sequence data. Numbers at branch indicate bootstrap proportions in 1,000 bootstrap pseudoreplications. Branches without BP values were not supported in $\geq 50 \%$ of the replicates. Bar equals 0.1 Kimura's two-parameter distance. "Asia" includes the western Oceanian islands. (B) Maximum parsimony (MP) cladogram using heuristic bootstrapping analysis (691 steps, $211 \mathrm{bp}$ informative under the condition of parsimony, consistency index $=0.56$ ). Branches without BP values were not supported in $\geq 50 \%$ of the replicates.

\section{DISCUSSION}

On the basis of differences in skull and external morphology, Greer (1970b) thought that Apterygodon and Dasia (sensu stricto) are monophyletic among the three arboreal genera formally assigned to Dasia (sensu lato), whereas Lamprolepis emerged independently from the Asian Mabuya-like stock. Later, he emphasized this view by arguing that the Apterygodon-Dasia lineage, Lamprolepis, and the terrestrial/ semi-fossorial Lygosoma constitute the three distinct phylogenetic lines independently derived from the Asian Mabuyalike stock (Greer, 1977). Karyological data (Ota et al., 1996) also offered a circumstantial support to Greer's (1977) view by indicating closer chromosomal similarities of the three arboreal genera with Asian species of Mabuya than with African congeners or other lygosomine groups. However, phylogenetic relationships inferred from DNA sequences in the present study do not support Greer's (1977) view with respect to the independent origins of Lamprolepis and Lygosoma, because these two genera exclusively constituted a cluster. Moreover, our results strongly suggest that the collective divergence of these two genera have occurred prior to the separation between the African Mabuya and the Asian
Mabuya-Apterygodon-Dasia clade. These may contradict with Greer's (1977) view, which seemingly assumed that Lamprolepis and Lygosoma have derived from the Mabuyalike stock within Asia.

Based on the morphological character, Greer $(1976,1977)$ assumed that the African endemic genera of the Mabuya group and African species of Mabuya were derived from the Mabuyalike stock through in situ continental radiation rather than from multiple colonizations from outside. Relationships depicted in Fig. 2A and 2B do not contradict with the postulated monophyly of African members of the Mabuya group, although the number and size of samples examined are too small to draw any definite conclusion by this result alone.

Considering our results, the Asian and African members of the Mabuya group are likely to constitute two major evolutionary lineages, which may be referred to as the Lygosoma and Mabuya subgroups. Ecological similarity, involving morphological specialization to arboreal habits (e.g., Greer, 1970b), between the Apterygodon-Dasia clade of the Mabuya subgroup and Lamprolepis of the Lygosoma subgroup thus seem to be attributable to the convergence rather than to the recent common ancestry. Morphological and karyological similarities among the Apterygodon-Dasia clade, Lamprolepis, 
Lygosoma and Asian species of Mabuya (Greer, 1970b, Ota et al., 1996) are supposed to be symplesiomorphy, although a few species of Lygosoma seems to have differentiated karyotypes (de Smet, 1981).

Greer (1970b, 1977) thought that Apterygodon and Dasia sensu stricto are monophyletic, constituting one of the distinct phylogenetic lineages derived from the Asian Mabuyalike stock. This view was confirmed by the present results. Apterygodon differs from Dasia and Mabuya in having an ectopterygoid process and a karyotype of $2 \mathrm{~N}=28$ format, and in lacking pterygoid teeth: both of the latter have basically $2 \mathrm{~N}=32$ format karyotypes and pterygoid teeth, and lack the ectopterygoid process (Greer, 1970b; Ota et al., 1996). Relationships illustrated by our analysis also favor views of the previous authors that those character states unique to Apterygodon have evolved from states of corresponding characters in Dasia (Greer, 1970b; Ota et al., 1996).

The nucleotide replacements between species of Mabuya were larger than those between some combinations of different genera. Moreover, Asian Mabuya were not exclusively clustered with African congeners in $\mathrm{NJ}$ analysis (Fig. 2A), although this relationship was not support in enough bootstrap proportion in MP analysis (Fig. 2B). These suggest the genetic heterogeneity and the non-monophyly of the genus. Further analysis for more species of Mabuya, including those from Madagascar and South America, are strongly desired to revise its systematics.

Recently Vietnascinsus was described from Vietnam as another genus of arboreal skinks monotypic with $V$. rugosus (Darevsky and Orlov, 1994). We have had no chance to directly examine this skink, but judging from the original description, it may be closest to Lamprolepis because both genera share a medial separation of palatal rami of pterygoids (Greer, 1970b; Darevsky and Orlov, 1994). We thus suspect that Vietnascinsus belongs to the Lygosoma subgroup of the Mabuya group. This view definitely needs further verifications.

\section{ACKNOWLEDGMENTS}

We would like to thank M. Matsui, T. Hidaka, S. Panha, M. Ishii, M. Kon, K. Araya, A. Mori, S. Furukawa, T. Hayashi, M. Toda, I. Miyagi, T. Toma, H. Hasegawa, A. Miyata, T. Chan-Ard, R. Goh, R. F. Goh, L. Saikeh, V. Chey, Labang D., A. A. Hamid, C. J. Chong, S. Cheng, the staff of the entomological section of the Forest Research Center, Sepilok, the staff of National Park and Wildlife and Forest Research Sections, Forest Department of Sarawak, and the staff of Hasanuddin University at Ujun Pandang, for providing us with various helps and encouragements during our fieldwork. We are also much indebted to M. Hori, M. Toriba, M. Hasegawa and Y. Misawa for providing specimens of Lamprolepis and African Mabuya, to M. Toda for helpful comments on an early draft of the manuscript, to N. Nikoh for helps and suggestions with statistical analyses, and to A. E. Greer for detailed information of his work and useful suggestions. Special thanks are due N. Satoh and members of his laboratory for continuous support for our laboratory experiments. Experiments were also carried out using the facility of the Kyoto University Museum.

Honda, Ota and Hikida are especially grateful to T. Hidaka, M. Matsui and I. Miyagi for providing opportunities to visit Malaysia, Thailand and Indonesia. Our research was partially supported by Grants-
in-Aid from the Japan Ministry of Education, Science, Sports and Culture (Overseas Researches Nos. 404326, 60041037, 61043033, 62041049, 63043037, 01041051, 02041051 and 03041044 to T. Hidaka, 04041068, 06041066 and 18041144 to M. Matsui, and 03041065 to I. Miyagi; Basic Researches C-09839024 to H. Ota and C-10836010 to T. Hikida), and a grant from the Fujiwara National History Foundation (to H. Ota).

\section{REFERENCES}

Anderson S, Bankier AT, Barrell BG, de Bruijin MHL, Coulson AR, Droun J, Eperon IC, Nierlich DP, Roe BA, Sanger F, Schreier $\mathrm{PH}$, Smith AJH, Staden R, Young IG (1981) Sequence and organization of the human mitochondrial genome. Nature 290: 457465

Baverstock PB, Donnellan SC (1990) Molecular evolution in Australian dragons and skinks: A progress report. Mem Queensland Mus 29: 323-331

Boulenger GA (1887) Catalogue of the lizards in the British Museum (Nat Hist). Vol 3, Taylor and Francis, London

Darevsky IS, Orlov NL (1994) Vietnascincus rugosus, a new genus and species of the Dasia-like arboreal skinks (Sauria, Scincidae) from Vietnam. Russ J of Herpetol 1: 37-41

de Smet WHO (1981) Description of the orcein strained karyotypes of 36 lizard species (Lacertilia, Reptilia) belonging to the families Teiidae, Scincidae, Lacertidae, Crodylidae and Varanidae (Autarchoglossa). Acta Zool Pathol Antverp 73: 73-118

Donnellan SC (1991a) Chromosomes of Australian lygosomine skinks (Lacertilia: Scincidae) I. The Egernia group: C-banding, silver staining, Hoechst 33258 condensation analysis. Genetica 83: 207-222

Donnellan SC (1991b) Chromosomes of Australian lygosomine skinks (Lacertilia: Scincidae) II. The genus Lamprophlis. Genetica 83: 223-234

Felsenstein J (1985) Confidence limits on phylogenies: An approach using the bootstrap. Evolution 39: 783-791

Greer AE (1970a) A subfamilial classifications of scincid lizards. Bull Mus Comp Zool 139: 151-184

Greer AE (1970b) The relationships of the skinks referred to the genus Dasia. Breviora 348: 1-30

Greer AE (1974) The genetic relationships of the scincid genus Leiolopisma and its relatives. Aust J Zool Suppl Ser 31: 1-67

Greer AE (1976) On the evolution of the Cape Verdes scincid lizard Macroscincus coctei. J Nat Hist 10: 691-712

Greer AE (1977) The systematics and evolutionary relationships of the scincid lizard genus Lygosoma. J Nat Hist 11: 515-540

Greer AE (1979) A phylogenetic subdivision of Australian skinks. Rec Aust Mus 32: 339-371

Greer AE (1989) The Biology and Evolutions of Australian Lizards. Surrey Beaty and Sons, Chipping Norton

Hardy GS (1979) The karyotypes of two scincid lizards and their bearing on relationships in the genus Leiolopisma and its relatives (Scincidae: Lygosominae). New Zealand J Zool 6: 609-612

Hedges SB, Nussbaum RA, Maxson LR (1993) Caecilian phylogeny and biogeography inferred from mitochondrial DNA sequences of the 12S rRNA and 16S rRNA genes (Amphibia: Gymnophiona). Herpetol Monogr 7: 64-76

Honda M, Ota H, Kobayashi M, Nabhitabhata J, Yong HS, Hikida T (1999) Phylogenetic relationships of the flying lizards, genus Draco (Reptilia, Agamidae). Zool Sci 16: 535-549

Horton DR (1972) Evolution of the genus Egernia (Lacertilia: Scincidae). J Herpetol 6: 101-109

Horton DR (1973) A new scincid genus from Southeast Asia. J Herpetol 7: $283-287$

Kimura M (1980) A simple method for estimating evolutionary rate of base substitutions through comparative studies of nucleotide 
sequences. J Mol Evol 16: 116-120

King M (1973) Karyotypic studies of some Australian Scincidae (Reptilia). Aust J Zool 21: 21-32

King M (1990) Chromosomal and immunogenetic data: A new respective on the origin of Australia's reptile. In "Cytogenetics of Amphibians and Reptiles" Ed by E Olmo, Birkhauser Verlag, Basel, pp 153-180

Kocher TD, Thomas WK, Meyer A, Edwards SV, Pääbo S, Villablanca FX, Wilson AC (1989) Dynamics of mitochondrial DNA evolution in animals: Amplifications and sequencing with conserved primers. Proc Nat Acad Sci USA 86: 189-191

Matsui M (1992) Systematic Zoology Vol 9 Vertebrate Ilb2, Reptilia. Nakayama Shoten, Tokyo (in Japanese)

Mittleman MB (1952) A generic synopsis of the lizard of subfamily Lygosominae. Smithsonian Misc Coll 117: 1-35

Nussbaum RA, Raxworthy CJ (1994) A new species of Mabuya Fitzinger (Reptilia: Squamata: Scincidae) from southern Madagascar. Herpetologica 50: 309-319

Ota H, Hikida T, Matsui M, Hasegawa M (1988) Karyotype of a scincid lizard, Carlia fusca, from Guam, the Mariana Islands. Zool Sci 5: 901-903

Ota H, Hikida T, Matsui M, Mori A (1991) Karyotypes of two water skinks of the genus Tropidophorus (Reptilia: Squamata) from Borneo. J Herpetol 25: 488-490

Ota H, Hikida T, Hasegawa M (1995) Karyotypes of two lygosomine lizards of the genus Emoia (Squamata: Scincidae) from Malaysia and Micronesia. Russ J Herpetol 2: 43-45

Ota H, Hikida T, Matsui M, Hasegawa M, Labang D, Nabhitabhata J (1996) Chromosomal variation in the scincid genus Mabuya and its arboreal relatives (Reptilia: Squamata). Genetica 98: 87-94
Saitou N, Nei M (1987) The neighbor-joining method: A new method for reconstructing phylogenetic trees. Mol Biol Evol 4: 406-425

Smith MA (1937) A review of the genus Lygosoma (Scincidae: Reptilia) and its allies. Rec Indian Mus 39: 213-234

Swofford DL (1993) Users Manual for PAUP 3.1: A Phylogenetic Analysis using Parsimony. Illinois Natural History Survey, Champain, Illinois

Thompson JD, Higgins DG, Gibson TJ (1994) Clustal W: Improving the sensitivity of progressive multiple sequence alignment through sequence weighting, position specific gap penalties and weight matrix choice. Nucl Acids Res: 4673-4680

Zug GR (1993) Herpetology. Academic Press, San Diego

(Received April 16, 1999 / Accepted June 25, 1999)

Appendix. Localities and catalogue numbers of specimens examined in this study. These specimens were deposited in the herpetological collection of the Department of Zoology, Kyoto University (KUZ). Apterygodon vittatus: Matang, Borneo, KUZ 27168. Dasia gricea: Gombak, Peninsular Malaysia, 22014. D. olivacea: Kaki Bukit, Peninsular Malaysia, 22142; Matang, Borneo, 27228. Lamprolepis smaragdina: Guam, Mariana Islands, 27775; Saipan, Mariana Islands, 35004. Lygosoma bowringii: Khao Chong, Thailand, 37884. Mabuya longicaudata: Lanyu, Taiwan, 35015. M. multifasciata: Mae Hon Son, Thailand, 32896. M. quiquetaeniata: Africa (detailed localities unknown), 45890. M. rudis: Dumoga-Bone, Sulawesi, 18572. M. striata: Kasenga, Zambia, 38944. Eumeces latiscutatus: Kyoto City, Japan, 46592. 